\title{
LETTER
}

\section{Scientific inquiry versus technology development in agriculture}

William Lockeretz and John Ikerd, in separate features in Vol. 8, No. 2 of $A J A A$, presented excellent comments on some challenges facing applied agricultural research scientists. Lockeretz gave a compelling argument questioning the relevance of drawing conclusions based on data with limited verification over various conditions. Ikerd pointed out the differences in how farmers and scientists approach knowledge and risk, even when they apparently are working on the same problem.

In recent years, these and related questions have troubled agricultural scientists. We have been told that we need a new paradigm, that we need new approaches to research, that scientists must have a new regard for indigenous knowledge, etc. Some scientists have coined terms like systems approach, cropping systems research, and participatory research, among others, in an attempt to break out of a traditional research mode that does not seem to meet their needs in promoting development of sustainable agriculture.

I think that these scientists are dissatisfied with the old way of doing science because of a conflict between means and ends. They are trying to use methods developed for scientific inquiry, whereas their true objectives would be better served by methods of technology development. Scientific inquiry seeks explanation. Technology development seeks invention.

Ikerd's description of the difference between farmers' objectives and those of scientists is correct. Farmers want to invent more productive management systems, while scientists profit only if they can explain, using statistically acceptable evidence, what might cause different management systems to produce different results. Invention is best when it is informed by science (assuming the science is correct), but an inventor may not want to wait for the scientific inquiry to be completed before advancing, and what is scientifically significant is not necessarily of agricultural significance.

If we understand that designing a sustainable agriculture is principally a matter of technological development, we see that the problem Lockeretz poses will persist. When scientists conduct research in cooperation with farmers, the farmers are in the role of inventors. The farmers will be ready to change treatments much sooner than the scientists. The farmer/inventor probably will have little patience to wait for a verified explanation of observed phenomena, except when all ideas on a practical solution to the problem have been exhausted.

Many of us believe that farmer-directed on-farm research helps fill the gap between scientific knowledge and farm practice. In medical terms we could consider on-farm research in vivo and experiment station research in vitro. Both are useful, but each has severe limitations; the system functions best when each informs the other. Scientists can help farmers by explaining their findings to them, and in turn can learn by observing farmers' results. The scientist is vital to the continued advancement of sustainable production systems. We should not be surprised, however, if some attempts at scientific inquiry on the farm actually impede the farmer's inventive progress.

We will be able to serve farmers better if we recognize that the development of improved farming systems does not require scientific inquiry at every point. Some farming system development projects take a research-and-development approach, rather than the academic scientist's normal research-and-publish approach. In my opinion, these projects will have the most practical and immediate impact on agriculture.

I hope that discussions of our scientific approach to applied agricultural research will consider the possibility that fostering invention is the most direct way to increase the sustainability of farming systems, even at the expense of scientific inquiry.

\section{Stewart B. Wuest}

Project Coordinator

STEEP II On-farm Testing Project

Department of Crop and Soil Sciences

Washington State University

Pullman, WA 99164-6420

\section{Position Available at Prescott College, AZ}

Prescott College seeks candidates for a new faculty position in Agroecology and Sustainable Living, to teach courses such as Agroecology; Sustainable Food Production Methods; Land Stewardship Skills; Food, Nutrition and World Hunger; Ecological Design; and Sustainable Community. Preference will be given to candidates with applied knowledge in appro- priate technologies, experience in Third World development, and interest in making use of the College's field station in Kino Bay, Mexico.

While the preferred degree qualification is an earned doctorate, applications are encouraged from exceptional candidates with other qualifications such as a Master's Degree and significant non-aca- demic experience. Starting date is August 10 ; starting salary is $\$ 30,000$. Send letter of application, unofficial graduate transcripts, and names of three references who may be contacted by telephone to Ms. Tricia Goffena, Assistant to the Dean of the RDP, Prescott College, 220 Grove Avenue, Prescott, AZ 86301. 